\title{
Guidelines seek unbiased recommendations
}

\author{
Alexander P. Vlaar ${ }^{1,9^{*}}{ }^{\mathbb{C}}$, Simon Oczkowski ${ }^{2,3,4}$, Gavin J. Murphy ${ }^{5}$, Anders Perner ${ }^{6}$, Gordon Guyatt ${ }^{2,3,4}$, \\ Joanna C. Dionne ${ }^{2,3,4}$ and Maurizio Cecconi ${ }^{7,8}$
}

Dear Editor,

We read with interest the editorial by Vincent which highlights the challenges in defining the optimal transfusion strategies in critically ill patient [1]. Although critical appraisal of guidelines is essential to ensure trustworthiness, we disagree with several points raised in the editorial.

First, we disagree with the claim that guidelines based upon RCTs are dangerous; for most clinical questions (including transfusion), high-quality RCTs remain the most trustworthy source of evidence. Although observational studies can provide invaluable insights and in some instances provide sufficiently high-quality evidence for guideline recommendations, they are invariablysubject to confounding by indication. Indeed, there are many examples of clinical treatments supported by observational data that were subsequently refuted by high-quality RCTs [2-6]. The true danger to patients and society is clinical practice informed by low-quality evidence resulting in patient harm and wasted resources.

Figure 1, and the associated text, is interesting [1]. If clinicians could clearly classify patients to those who need transfusion and those who don't, such patients should not be entered in clinical trials. Unfortunately, in most instances, they cannot. No doubt groups are heterogenous with respect to benefit, but until clinical criteria or biological enrichment strategies for identifying the populations for whom different thresholds are appropriate are well established, RCTs remain the ideal study methodology.
Second, we agree that RCTs that exclude numerous patients can lack generalizability. For this reason, the panel chose to make separate recommendations, where possible, for specific populations of critically ill patients. While the original TRICC trial [7] did exclude a high proportion of screened patients (87\%), the more recent trials included in the guideline had higher enrollment rates and well-documented exclusion criteria [8-10]. An overview of inclusion/exclusion decisions for the RCTs included in the guidelines is presented in Table 1 . While high rates of exclusion also raise the possibility of selection bias, virtually all trials were at low risk of bias with respect to randomization, allocation concealment, and use of intention-to-treat alongside per-protocol analyses, all of which minimize the risk of systematic differences between the baseline characteristics and prognoses between the allocation arms [11].

We do not have evidence in non-bleeding critically ill patients that individualized transfusion targets are better than crude hemoglobin ( $\mathrm{Hb})$. This specific question was assessed by the guideline panel, which identified $\mathrm{ScvO}_{2}$, arteriovenous oxygen difference, cerebral tissue oxygenation, plasma lactate, and veno-arterial $\mathrm{CO}_{2}$ gradient as potential alternative triggers. Only one (cerebral oxygenation during cardiac surgery) has been evaluated in an RCT [12]. This trial of 204 patients found similar transfusion rates, biomarkers of brain, kidney and myocardial injury, and costs in both arms. The panel concluded that insufficient evidence exists to justify the use of any of these "alternative" transfusion triggers. We do not know if they would result in improved patient outcomes or reduce the use of unnecessary blood products in non-

bleeding critically ill patients [13]. The panel agrees that before widespread clinical adoption, alternative transfusion triggers should be rigorously evaluated in RCTs. We welcome such trials and hope that such techniques may supplement $\mathrm{Hb}$-based thresholds in the future. 
Table 1 Overview of patient exclusion reasons and percentage of RBC transfusion trials included in the ESICM transfusion guideline part I

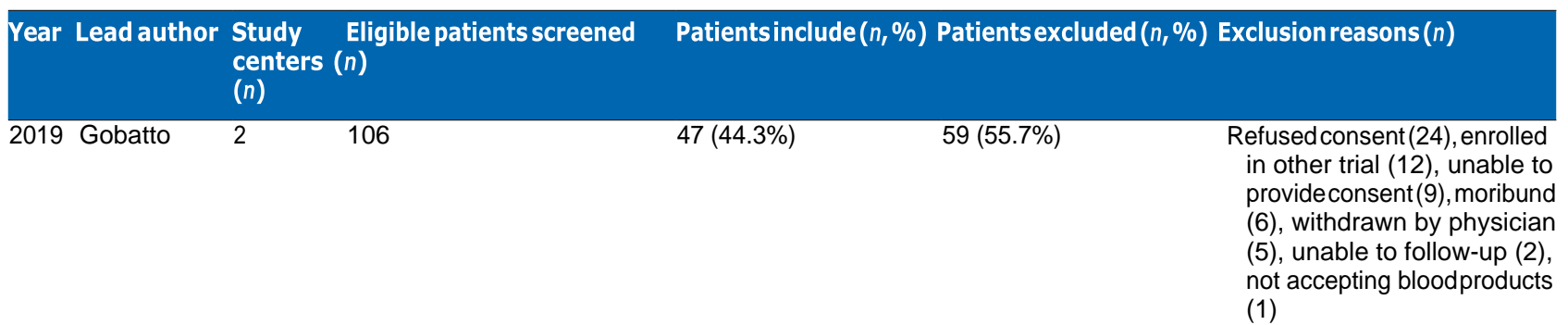

\begin{tabular}{|c|c|c|c|c|}
\hline 2018 Laine & 1 & 84 & 80 (95\%) & $4(5 \%)$ \\
\hline 2017 Bergamin & 1 & 1223 & $300(24.5 \%)$ & 923 (75.5\%) \\
\hline
\end{tabular}

Declined participation (4)

Hematologic malignancy (407), enrolled in other trial (145), life expectancy under $24 \mathrm{~h}(132)$, Karnofsky score under 50 (83), coagulopathy (54), DNR (32), life-threatening bleeding (32), end-stage renal disease (22), priortransfusionreaction(16)

\begin{tabular}{|c|c|c|c|c|c|c|}
\hline 2017 & Mazer & 73 & 14,702 & $5243(35.7 \%)$ & $9459(64.3 \%)$ & $\begin{array}{l}\text { Patient refusal (2466), unable } \\
\text { to provide consent (889), } \\
\text { enrolledinotherstudy (1108), } \\
\text { unable to receive blood prod- } \\
\text { ucts(106), notapproached } \\
\text { forconsent(1619), change in } \\
\text { surgery schedule (375), other } \\
\text { (2896) }\end{array}$ \\
\hline 2017 & Koch & 2 & 7104 & $722(10.2 \%)$ & $6382(89.8 \%)$ & $\begin{array}{l}\text { Off-pump procedure or surgeon } \\
\text { decision (6036), not con- } \\
\text { sented (300), administrative } \\
\text { reasons (13), surgery canceled } \\
\text { (11), declined participation } \\
\text { (9), enrolled in other study (7), } \\
\text { staff refusal (6) }\end{array}$ \\
\hline 2015 & Mazza & 3 & 63 & $63(100 \%)$ & Not applicable & Not applicable \\
\hline 2015 & Murphy & 17 & 4582 & 2007 (43.8\%) & $2575(56.2 \%)$ & $\begin{array}{l}\text { Not approached for consent } \\
\text { (1863), did not consent (2719), } \\
\text { surgery notperformed(26), } \\
\text { clinician withdrawal pre- } \\
\text { surgery (17), withdrawpost- } \\
\text { surgery pre-randomization } \\
\text { (16), found to be ineligible } \\
\text { post-op (9), trial ended prior } \\
\text { toOR(9), patientwithdrawal } \\
\text { pre-surgery (7), missed on } \\
\text { admission dueto stafferror } \\
\text { (5), patient died in OR (4), } \\
\text { patientwithdrawal post-sur- } \\
\text { gery pre-randomization(1) }\end{array}$ \\
\hline 2015 & Almedia & 1 & 234 & $198(84.6 \%)$ & $36(15.4 \%)$ & $\begin{array}{l}\text { DNR (21), enrolled in other trial } \\
\text { (8), unable to consent (2), } \\
\text { activebleed (1), coagulopathy } \\
\text { (1), chronic anemia (1) }\end{array}$ \\
\hline 2014 & Holst & 32 & 1224 & $1005(82 \%)$ & $219(18 \%)$ & $\begin{array}{l}\text { Received transfusion in ICU } \\
\text { (137), could not obtain } \\
\text { consent (34), acute coronary } \\
\text { syndrome (20), withdrew } \\
\text { active therapy (17), life- } \\
\text { threatening bleeding (16), } \\
\text { previous transfusion reaction } \\
\text { (4), declinedtransfusion (3), } \\
\text { acute burns (3) }\end{array}$ \\
\hline
\end{tabular}


Table 1 (continued)

\begin{tabular}{|c|c|c|c|c|c|}
\hline Year Lead author & $\begin{array}{l}\text { Study } \\
\text { centers } \\
\text { (n) }\end{array}$ & $\begin{array}{l}\text { Eligible patients screened } \\
(n)\end{array}$ & Patientsinclude $(n, \%)$ & Patients excluded $(n, \%)$ & Exclusion reasons ( $n$ ) \\
\hline 2014 Robertson & 2 & 598 & 200 (33.4\%) & $398(66.6 \%)$ & $\begin{array}{l}\text { Fixed, dilated pupils (91), unable } \\
\text { to locate next of kin (86), } \\
\text { severe preexisting disease } \\
\text { (67), penetrating injury (53), } \\
\text { life-threatening systemic } \\
\text { injury (53), refusedconsent } \\
\text { (37), other (95) }\end{array}$ \\
\hline 2013 Walsh & 6 & 287 & $100(34.8 \%)$ & 187 (65\%) & $\begin{array}{l}\text { Intracranial hemorrhage (25), } \\
\text { expected survival less than } \\
48 \mathrm{~h}(18) \text {, clinician refusal (18), } \\
\text { enrolled in other trial (17), no } \\
\text { next of kin (17), follow-up not } \\
\text { feasible (12), brain injury (11), } \\
\text { communication difficulties } \\
\text { (3), no research staff available } \\
\text { (2) erythropoietin therapy } \\
\text { (2), bleeding (1), transfusion } \\
\text { objection (1) }\end{array}$ \\
\hline 2013 Carson & 8 & 452 & $110(24.3 \%)$ & $342(75.7 \%)$ & $\begin{array}{l}\text { Patient refused (198), physician } \\
\text { refused (93), patient dis- } \\
\text { charged before consent ( } 31)\end{array}$ \\
\hline 2012 Shehata & 1 & 1854 & $219(11.8 \%)$ & $1635(88.2 \%)$ & $\begin{array}{l}\text { Coordinator unavailable (624), } \\
\text { other (393), enrolled in } \\
\text { another study (260), non- } \\
\text { participating surgeon(188), } \\
\text { unable to give consent(141), } \\
\text { autologous premonition(29) }\end{array}$ \\
\hline 2011 Cooper & 2 & Not reported & 34 & Not reported & Not reported \\
\hline 2010 Hajjar & 1 & 1765 & $512(29 \%)$ & $1084(71 \%)$ & $\begin{array}{l}\text { Chronic anemia (205), did } \\
\text { not provide consent (169), } \\
\text { enrolled in other study (124), } \\
\text { emergency procedure (123), } \\
\text { surgery without bypass (105), } \\
\text { coagulopathy (93), aortic } \\
\text { procedure (90), congenital } \\
\text { heart defect (85), endocarditis } \\
\text { (82), thrombocytopenia (78), } \\
\text { ESRD (73), unable to receive } \\
\text { blood (26) }\end{array}$ \\
\hline 2010 Naidech & 1 & $\begin{array}{l}230 \text { screened, eligiblenot } \\
\text { reported }\end{array}$ & $44(19 \%)$ & $86(81 \%)$ & $\begin{array}{l}\text { No consent (31), inclusion } \\
\text { exclusion reasons not given } \\
\text { (155) }\end{array}$ \\
\hline 1999 Hébert & 25 & 3206 & $838(26 \%)$ & $2368(74 \%)$ & $\begin{array}{l}\text { Physician refusal (598), patient/ } \\
\text { family refusal (603), previous } \\
\text { transfusion(297), timelimita- } \\
\text { tion (256), no next of kin (174), } \\
\text { languagebarrier (36), other } \\
\text { reasons (404) }\end{array}$ \\
\hline 1999 Bracey & 1 & 428 & Not reported & Not reported & Not reported \\
\hline 1995 Hébert & 5 & Not reported & 69 & Not reported & Not reported \\
\hline
\end{tabular}

Third, the potential harms of restrictive transfusion in the studies highlighted in the editorial [8] are based upon a very selective review of the evidence. Unfortunately, there are even factually incorrect references in the editorial, including in a reference to the TRICC trial: "Areanalysis of the initial study by Hebert et al. revealed a harmful effect of restrictive transfusion strategy in patients with ischemic heart disease and in those with high APACHE scores [6]." This is incorrect as the original TRICC trial studied APACHE II scores. The trial suggested benefit from restrictive transfusion in lower APACHE II scores. There was no difference in harm with higher APACHE II 
scores. The reanalysis did not include APACHE II at all. The trials referenced in the editorial $[7,8]$ were included in a recent meta-analysis, which focused on patients with cardiovascular disease, and found no compelling evidence of harm [14]. Most trials included in theguideline showed no harm for the populations in which the editorial proposed possible harm. The misleading conclusions drawn from a selective reading of the evidence are one of the reasons why rigorous and transparent guidelines are necessary. The guideline utilized systematic reviews of the literature, which included all potentially relevant studies to develop non-biased recommendations.

Fourth, we emphasize that guidelines are not "rules" and that clinical judgement is always required when applying any evidence at the bedside. As clinicians, we must consider numerous factors when deciding to transfuse (e.g., rate of $\mathrm{Hb}$ decline, co-morbidities, patient willingness to accept transfusion). However, clinical judgement is also imperfect. In this regard, RCTs and guidelines assist clinicians and institutions to set general transfusion thresholds where benefits appear marginal for most patients-without them we would likely still be applying transfusion thresholds of $10 \mathrm{~g} / \mathrm{dL}$, with unnecessary use of blood products. Another approach is to consider liberal transfusion to be a novel intervention. We would argue that there is insufficient evidence to justify changing from a restrictive to a liberal transfusion practice based upon the existing data (even the highly selected evidence chosen for the editorial). Recognizing the need for clinical judgement, alongside the limitations of the existing evidence, most of the panel's guideline statements are conditional/weak recommendations rather than strong recommendations.

Lastly, while we acknowledge the general enthusiasm toward big data and artificial intelligence, a recent systematic review found no performance benefit of machine learning over "traditional" logistic regression and clinical prediction models [15]. In addition, Collins and Moons recently have highlighted several issues regarding artificial intelligence, including over prediction, poor validation, lack of transparency, and poor reproducibility[16]. Clearly, there is still a need for methodologically rigorous RCTs, which remain the best design to evaluate the effectiveness and harm of clinical interventions and should form the basis of trustworthy clinical practice guidelines.

\footnotetext{
Author details

${ }^{1}$ Department of Intensive Care Medicine, Amsterdam UMC, Location AMC, Amsterdam, The Netherlands. ${ }^{2}$ Department of Medicine, McMaster University, Hamilton, Canada. ${ }^{3}$ Guidelines in Intensive Care, Development and Evaluation (GUIDE) Group, Hamilton, Canada. ${ }^{4}$ Department of Health Research Methods, Evidence, and Impact, McMaster University, Hamilton, Canada. ${ }^{5}$ Department of Cardiovascular Sciences, NIHR Leicester Biomedical Research Centre-Cardiovascular, College of Life Sciences, University of Leicester, Leicester LE3 9QP,
}

Canada. ${ }^{6}$ Department of IntensiveCare, Rigshospitalet, University of Copenhagen, Copenhagen, Denmark. ${ }^{7}$ Department of Anaesthesia and Intensive Care Medicine, Humanitas Clinical and Research Centre-IRCCS, Rozzano, Milan, Italy. ${ }^{8}$ Humanitas University, via Rita Levi Montalcini, Pieve Emanuele, Milan, Italy. ${ }^{9}$ Department of Intensive Care Medicine, Amsterdam UMC, Room, C3-430, Meibergdreef 9, 1105 AZ Amsterdam, The Netherlands.

\section{Acknowledgements}

Methodological support for this project was provided by Guidelines in Intensive Care, Development, and Evaluation (GUIDE group—https://guidecanad a.org).

On behalf of the ESICM Transfusion Task Force: Sanne de Bruin (Department of Intensive Care Medicine, Amsterdam UMC, location AMC, Amsterdam, The Netherlands), Marije Wijnberge (Department of Intensive Care Medicine, Amsterdam UMC, location AMC, Amsterdam, The Netherlands; Department of Anaesthesiology, Amsterdam UMC, location AMC, Amsterdam, The Netherlands), Massimo Antonelli (Department of Anaesthesiology and Intensive Care Medicine, Fondazione Policlinico Universitario A.Gemelli IRCCS, Rome, Italy; Istituto di Anaesthesiology e Rianimazione Università Cattolica del Sacro Cuore, Rome, Italy), Cecile Aubron (Department of Intensive Care Medicine, Centre Hospitalier Régional et Universitaire de Brest, site La Cavale Blanche, Université de Bretagne Occidentale, Brest, France), Philippe Aries (Department of IntensiveCare Medicine, Centre Hospitalier RégionaletUniversitaire deBrest, site La Cavale Blanche, Université de Bretagne Occidentale, Brest, France), Jacques Duranteau (Department of Anaesthesiaand Intensive Care, Hôpitauxuniversitaires Paris Sud (HUPS)), Nicole P. Juffermans (Department of Intensive Care Medicine, Amsterdam UMC, location AMC, Amsterdam, The Netherlands), Jens Meier(Department of Anesthesiology and Critical Care Medicine, Faculty of Medicine, Kepler University, Linz, Austria), Riccardo Abbasciano (NIHR Leicester Biomedical Research Centre-Cardiovascular, Department of Cardiovascular Sciences, College of Life Sciences, University of Leicester, Leicester, LE39QP), Marcella Muller (Department of Intensive Care Medicine, Amsterdam UMC, location AMC, Amsterdam, The Netherlands), Akshay Shah (Radcliffe Department of Medicine, University of Oxford, Oxford, UK; Adult Intensive Care Unit, John Radcliffe Hospital, Oxford, UK), Sofie Rygaard (Anaesthetics, Critical Care, and Pain Medicine, University of Edinburgh, Edinburgh, Scotland), Timothy S. Walsh (Anaesthetics, Critical Care, and Pain Medicine, University of Edinburgh, Edinburgh, Scotland).

Conflicts of interest

The authors declare that they have no competing interests.

\section{References}

1. VincentJL (2020) Transfusion thresholds: the dangers of guidelines basedonrandomized controlledtrials. Intensive CareMed.https://doi. org/10.1007/s00134-019-05889-3

2. Koch CG, Li L, Sessler DI, Figueroa P, Hoeltge GA, Mihaljevic Tet al (2008) Duration of red-cell storage and complications after cardiac surgery. N Engl J Med 358(12):1229-1239

3. Steiner ME, Ness PM, Assmann SF, Triulzi DJ, Sloan SR, Delaney M et al (2015) Effects of red-cell storage duration on patients undergoing cardiac surgery. N Engl J Med 372(15):1419-1429

4. Vandenbroucke JP (2009) The HRT controversy: observational studies and RCTs fall in line. Lancet 373(9671):1233-1235

5. Dransfield MT, Voelker H, Bhatt SP, Brenner K, Casaburi R, Come CE etal (2019) Metoprololfor the prevention of acute exacerbations of COPD.N Engl J Med381(24):2304-2314 
6. National HeartL, Blood Institute PCTN, GindeAA, Brower RG, Caterino JM, FinckLetal (2019) Early high-dosevitamin D3 for criticallyill, vitamin D-deficient patients. N Engl J Med 381(26):2529-2540

7. Hebert PC, Wells G, Blajchman MA, Marshall J, Martin C, Pagliarello G etal (1999) A multicenter, randomized, controlled clinical trial of transfusion requirements in critical care. Transfusion requirements in critical care investigators, Canadian Critical Care Trials Group. N Engl J Med 340(6):409-417

8. Murphy GJ, Pike K, Rogers CA, Wordsworth S, Stokes EA, Angelini GD et al (2015) Liberal or restrictive transfusion after cardiac surgery. N Engl J Med 372(11):997-1008

9. Holst LB, Haase N, Wetterslev J, Wernerman J, Guttormsen AB, Karlsson S et al (2014) Lower versus higher hemoglobin threshold for transfusion in septic shock. N Engl J Med 371(15):1381-1391

10. Mazer CD, Whitlock RP, Fergusson DA, Hall J, Belley-Cote E, Connolly K et al (2017) Restrictive or liberal red-cell transfusion for cardiac surgery. N Engl J Med377(22):2133-2144

11. Mansournia MA, Higgins JP,Sterne JA, Hernan MA (2017)Biases in randomized trials: a conversation between trialists and epidemiologists. Epidemiology 28(1):54-59
12. Rogers CA, Stoica S, Ellis L, Stokes EA, Wordsworth S, Dabner Letal (2017) Randomized trial of near-infrared spectroscopy for personalized optimization of cerebral tissue oxygenation during cardiac surgery. $\mathrm{Br} \mathrm{J}$ Anaesth 119(3):384-393

13. Vlaar AP, Oczkowski S, de Bruin S, Wijnberge M, Antonelli M, Aubron C etal (2020) Transfusion strategies in non-bleeding critically ill adults: a clinical practice guideline from the European Society of Intensive Care Medicine. Intensive Care Med. https://doi.org/10.1007/s00134-019-05884-8

14. Carson JL, Stanworth SJ, Alexander JH, Roubinian N, Fergusson DA, Triulzi DJ etal (2018) Clinical trials evaluating red blood cell transfusion thresholds: an updated systematic review and with additional focus on patients with cardiovascular disease. Am Heart J 200:96-101

15. Christodoulou E, Ma J, Collins GS, Steyerberg EW, Verbakel JY, Van Calster $B(2019)$ Asystematic review shows no performance benefit of machine learning over logistic regression for clinical prediction models. J Clin Epidemiol 110:12-22

16. Collins GS, Moons KGM (2019) Reporting of artificial intelligence prediction models. Lancet393(10181):1577-1579 